\title{
Prediction of tensile strength of sawn timber: models for calculation of yield in strength classes
}

\author{
Andreas Briggert $\cdot$ Anders Olsson · Jan Oscarsson
}

Received: 14 November 2019/ Accepted: 11 April 2020/Published online: 11 May 2020

(C) The Author(s) 2020

\begin{abstract}
In Europe, strength classes for structural timber and glulam lamellae are defined by minimum requirements of characteristic values of the grade determining properties (GDPs). To fulfill these minimum requirements of characteristic values in the daily production at sawmills, indicating properties (IPs) to GDPs are calculated for each board and based on predetermined limits of the IPs (settings) boards are assigned to the graded class, or rejected. The aims of this paper is to address and discuss two different grading procedures/models that can be applied when settings for IPs that reflects a local board property are derived and to show how the yield in different T-classes depend on the model applied. It is not always that a board's weakest cross-section is evaluated in a destructive test. An IP representing a local board property can therefore be determined either as the lowest property of the tested part of the board or as the lowest property along the whole board when applied to derive settings. Results presented in this paper show that too low settings and too large yields are obtained when the latter IP is employed. Similarly,
\end{abstract}

A. Briggert $(\varangle) \cdot$ A. Olsson · J. Oscarsson

Department of Building Technology, Linnaeus

University, Växjö, Sweden

e-mail: andreas.briggert@lnu.se

A. Olsson

e-mail: anders.olsson@1nu.se

J. Oscarsson

e-mail: jan.oscarsson@lnu.se
IPs reflecting a global board property, like axial dynamic MOE, also give too low settings and too high yield in strength classes. This paper is the second and closing part of a series of two paper on prediction of GDPs and procedures for grading sawn timber into T-classes.

Keywords Grading of timber - Laser scanning · Fibre direction - Dynamic modulus of elasticity . Norway spruce

\section{List of symbols}

$E_{\mathrm{a}, 90, \text { nom }} \quad$ Lowest local axial modulus of elasticity (MOE) of the destructivly tested part of the board, calculated on the basis of observed fibre directions

$E_{\mathrm{a}, 90, \text { nom,test }} \quad$ Lowest local axial MOE of the destructivly tested part of the board, calculated on the basis of observed fibre directions, i.e.

$E_{\mathrm{a}, 90, \text { nom,test }}=E_{a, 90, \text { nom }}$

$E_{\mathrm{a}, 90, \text { nom,whole }}$ Lowest local axial MOE of the whole board, calculated on the basis of observed fiber directions

$E_{\mathrm{b}, 90, \text { nom }} \quad$ Lowest local bending MOE of the destructivly tested part of the board, calculated on the basis of observed fibre directions 


\section{$E_{\mathrm{b}, 90, \text { nom,test }}$}

$E_{\mathrm{b}, 90, \text { nom,whole }}$

$E_{\text {dyn, }, 12 \%}$

$E_{\mathrm{t}, 0,12 \%}$

$E_{\mathrm{t}, 0,12 \% \text {,test }}$

$E_{\mathrm{t}, 0,12 \% \text {,whole }}$

$E_{\mathrm{t}, 0, \text { mean }}$

$f_{\mathrm{t}, 0, \mathrm{~h}}$

$f_{\mathrm{t}, 0, \mathrm{~h}, \text { test }}$

$f_{\mathrm{t}, 0, \mathrm{~h}, \text { whole }}$

$f_{\mathrm{t}, 0, \mathrm{k}}$

$\mathrm{IP}_{\mathrm{E}, \mathrm{a}}$

$\mathrm{IP}_{\mathrm{E}, \mathrm{b}}$

$\operatorname{IP}_{\mathrm{E}, \mathrm{b}, \mathrm{f}, 1}(u, v)$
Lowest local bending MOE of the destructivly tested part of the board, calculated on the basis of observed fibre directions, i.e.

$E_{\mathrm{b}, 90, \text { nom,test }}=E_{\mathrm{b}, 90, \text { nom }}$

Lowest local bending MOE of the whole board, calculated on the basis of observed fibre directions

Axial dynamic MOE at a moisture content of $12 \%$

Grade determining tensile MOE parallel to grain

Grade determining tensile MOE parallel to grain i.e.

$E_{\mathrm{t}, 0,12 \% \text {,test }}=E_{\mathrm{t}, 0,12 \%}$

Tensile MOE parallel to grain of the weakest cross-section of the whole board

Mean characteristic MOE parallel to grain

Grade determining tensile strenght parallel to grain

Grade determining tensile strenght parallel to grain, i.e. $f_{\mathrm{t}, 0, \mathrm{~h}, \mathrm{test}}=f_{\mathrm{t}, 0, \mathrm{~h}}$

Tensile strenght of the weakest cross-section of the whole board 5-percentile characteristic tensile strength parallel to grain Indicating property (IP) for prediction of the grade determining properties (GDPs), derived by means of multiple linear regression using $E_{\mathrm{a}, 90, \text { nom,test }}$ and $E_{\mathrm{dyn}, 12 \%}$ as predictor variables and the investigated GDP as dependent variable

IP for prediction of the GDPs, derived by means of multiple linear regression using $E_{\mathrm{b}, 90, \text { nom,test }}$ and $E_{\text {dyn }, 12 \%}$ as predictor variables and the investigated GDP as dependent variable

IP for prediction of strength, derived by means multiple linear regression using $E_{\mathrm{b}, 90, \text { nom,test }}$ and $E_{\mathrm{dyn}, 12 \%}$ as predictor variables and $f_{\mathrm{t}, 0, \mathrm{~h}, \text { test }}$ as dependent variable
$\operatorname{IP}_{\mathrm{E}, \mathrm{b}, \mathrm{f}, 2}(u, v) \quad$ IP for prediction strength, derived by means multiple linear regression using $E_{\mathrm{b}, 90, \text { nom,whole }}$ and $E_{\mathrm{dyn}, 12 \%}$ as predictor variables and $f_{\mathrm{t}, 0, \mathrm{~h}, \text { test }}$ as dependent variable

$\rho_{12 \%} \quad$ Grade determining density

$\rho_{\mathrm{k}} \quad$ 5-percentile characteristic density

$\rho_{\mathrm{s}, 12 \%} \quad$ Board density at a moisture content of $12 \%$

$r^{2} \quad$ Coefficient of determination

\section{Introduction}

This paper is the second and closing part of a series of two papers on prediction of grade determining properties (GDPs) and procedures for grading sawn timber into T-classes for use as glulam lamellae.

\subsection{Background}

Strength classes for structural timber and glulam lamellae are defined by requirements of the GDPs. Structural timber is graded to C-classes (softwood) and D-classes (hardwood). The boards assigned to such classes must have a 5-percentile characteristic bending strength $\left(f_{\mathrm{m}, \mathrm{k}}\right)$, a 5-percentile characteristic density $\left(\rho_{\mathrm{k}}\right)$ and a mean characteristic modulus of elasticity $(M O E)$ parallel to grain $\left(E_{\mathrm{m}, 0, \text { mean }}\right)$ that exceed the minimum requirements of the graded class. Similarly glulam lamellae, which are graded to T-classes, must have a 5-percentile characteristic tensile strength parallel to grain $\left(f_{\mathrm{t}, 0, \mathrm{k}}\right)$, a 5-percentile characteristic density and a mean characteristic $M O E$ parallel to grain $\left(E_{\mathrm{t}, 0, \text { mean }}\right)$ that exceed the minimum requirements of the graded T-class.

The minimum requirements of 5-percentile characteristic strength and 5-percentile characteristic density of each class are given in EN 338 [1]. To fulfil these requirements for a certain class, at least $95 \%$ of the assigned boards must have higher strength and higher density, respectively than the corresponding characteristic values of that class. For each class, EN 338 [1] also includes a requirement of mean characteristic MOE parallel to grain, i.e. for $E_{\mathrm{m}, 0 \text {, mean }}$ or $E_{\mathrm{t}, 0 \text {,mean }}$. The minimum requirement of $E_{\mathrm{m}, 0 \text {,mean }}$ or $E_{\mathrm{t}, 0 \text {,mean }}$ of a certain class is, however, determined, in 
accordance with EN 384 [2], as the requirement given in EN 338 [1] multiplied by a factor of 0.95 .

Development and evaluation of a method for machine strength grading consist of two parts. The first part concern definitions and calculations of indicating properties (IPs) and determination of GDPs for a sample of boards and evaluation of the statistical relationship between them. The second part consists of determining thresholds for the IPs, or settings as it is referred to in the standards, such that all the minimum requirements of characteristic values of a graded class are fulfilled, if boards with IPs that exceed the determined settings are assigned to the class. In Prediction of tensile strength of sawn timber: Definitions and performance of indicating properties based on surface laser scanning and dynamic excitation [3] the GDPs for T-classes, i.e. tensile strength $\left(f_{\mathrm{t}, 0, \mathrm{~h}}\right)$, density $\left(\rho_{12 \%}\right)$ and tensile $\operatorname{MOE}\left(E_{\mathrm{t}, 0,12 \%}\right)$, and several IPs were defined. Coefficients of determination and standard errors of estimate (SEEs) between GDPs and suggested IPs were calculated and presented. This was done using a sample of Norway spruce boards from Finland, Norway and Sweden, in total 967 pieces, of different dimension. Settings for IPs corresponding to $\mathrm{T}$-classes were not derived in that paper and potential yield in different $\mathrm{T}$-classes and combinations of T-classes was not presented, but it was mentioned therein that the process of calculating settings and yield is a delicate matter that needs to be described and discussed in detail.

As regards suggested IPs, [3] includes a detailed description of the non-destructive measurements carried out in this investigation. The machine measurements consisted of surface laser scanning, X-ray scanning and dynamic excitation for determination of boards' in-plane fibre directions at longitudinal surfaces and dimensions, local densities and first axial resonance frequency, respectively. On the basis of these measurement results, the following IPs were defined: board density $\left(\rho_{\mathrm{s}, 12 \%}\right)$, dynamic $M O E$ $\left(E_{\mathrm{dyn}, 12 \%}\right)$, local axial MOE $\left(E_{\mathrm{a}, 90, \text { nom }}\right)$, local bending $\operatorname{MOE}\left(E_{\mathrm{b}, 90, \text { nom }}\right), \mathrm{IP}_{\mathrm{E}, \mathrm{a}}$ and $\mathrm{IP}_{\mathrm{E}, \mathrm{b}}$. The latter two were determined by combining $E_{\mathrm{dyn}, 12 \%}$ with $E_{\mathrm{a}, 90, \text { nom }}$ $\left(\mathrm{IP}_{\mathrm{E}, \mathrm{a}}\right)$ or $E_{\mathrm{b}, 90, \text { nom }}\left(\mathrm{IP}_{\mathrm{E}, \mathrm{b}}\right)$ by means of multiple linear regression.

Bending strength and tensile strength, the former a GDP for C- and D-classes and the latter, as mentioned previously, a GDP for T-classes, are the GDPs most difficult to predict [4], and are as shown in [5, 6] decisive for the yield of strength classes. For the sample used in this investigation, the best predictions of $f_{\mathrm{t}, 0, \mathrm{~h}}$ were achieved using $\mathrm{IP}_{\mathrm{E}, \mathrm{b}}$ for which coefficients of determination of 0.65 and 0.66 (linear regression) were reached using data from measurements obtained before and after planing of boards, respectively [3]. For prediction of $E_{\mathrm{t}, 0,12 \%}$, application of the three IPs $E_{\mathrm{dyn}, 12 \%}, \mathrm{IP}_{\mathrm{E}, \mathrm{a}}$ and $\mathrm{IP}_{\mathrm{E}, \mathrm{b}}$ resulted in similar coefficients of determination, just above 0.8 both before and after planing. The best predictor of $\rho_{12 \%}$ was $\rho_{s, 12 \%}$ for which coefficients of determination of 0.90 (before planing) and 0.92 (after planing) were achieved. Note that destructive tests carried out to determine GDPs were made after planing.

Regarding the European standard EN 14081-2 [7] (and EN 14081-2 [8] which was recently published) in which the procedures for calculation of settings and yield in C-/D- and T-classes are regulated, it should be noted that there is no distinction between IPs that reflect a local property along a board, such as $E_{\mathrm{a}, 90, \text { nom }}$ and $E_{\mathrm{b}, 90, \text { nom }}$, and IPs that reflect a global property of a board, such as $\rho_{\mathrm{s}, 12 \%}$ and $E_{\mathrm{dyn}, 12 \%}$. There is, however, a fundamental difference between local- and global properties, which is due to the fact that it is not always the very weakest cross-section of a board that is evaluated in a destructive test. Sometimes the anticipated weakest cross-section is too close to one of the board's ends and can therefore not be tested (in such cases it is permitted in accordance with EN 384 [2] to test a board's second anticipated weakest crosssection), and sometimes the actually weakest crosssection is not the one that was anticipated. The value of an IP that is based on a local property will differ if it is defined as the lowest local property along the entire length of the board or as the lowest local property along the part of the board actually tested, i.e. the part of the board over which strength is evaluated. No similar distinction is possible for an IP that simply represents a global property of the entire board. Thus it should be discussed in detail, when settings and yield are calculated, how to define and employ IPs that are based on local properties along boards, and to what extent the results obtained are comparable to those obtained using IPs based on global board properties. This issue has already been recognized in [9] and [10] which has shown that that machine strength grading of structural timber based on IPs that simply represents a global property, like dynamic MOE or board density, give too high yield in strength classes. Their findings 
and suggestions on how to compensate for this effect are discussed and compared with the findings of the present investigation in Sect. 4.

\subsection{Purpose and aims}

The results presented in this series of two papers are based on a full-scale investigation aiming at deriving IPs and determining settings and yield for T-classes using a grading method similar to the one presented in [11]. The aims of the first paper [3] (Part 1) were to evaluate the statistical relationship between suggested IPs and GDPs for a sample including a total number of 967 boards and to evaluate if it was possible to utilise in-plane fibre directions obtained when laser scanning sawn rather than planed board surfaces for accurate grading. The aims of the current paper are to

- present two different, applicable procedures for determination of settings for grading methods based on IPs reflecting local board properties,

- determine settings for T-classes using $\mathrm{IP}_{\mathrm{E}, \mathrm{b}}$ for strength, $E_{\mathrm{dyn}, 12 \%}$ for MOE and $\rho_{\mathrm{s}, 12 \%}$ for density and show how the yield in different strength classes depend on the procedure used for determination of settings and

- discuss implications of the results presented on machine strength grading standards.

Settings, and thus the yields presented in this paper, are determined using the standard EN 14081-2 [7]. A new version of this standard (EN 14081-2 [8]) is available. Although there are changes in this new standard regarding sample sizes etc., the two different procedures for calculation of settings and yield described in this paper can still be applied.

\section{Calculation of settings and yield}

When deriving settings for a strength class, a sample including more than 900 boards must be used (EN 14081-2 [7]). This sample shall be divided into at least four sub-samples and the minimum number of boards in each sub-sample shall be 100 . The timber used in this investigation were divided into five sub-samples: Finland, Norway, south Sweden, mid Sweden and north Sweden. A thorough description of sampling procedure, origin of boards, board dimensions, number of boards in each sub-sample and number of boards of each dimension is given in [3].

In addition to what is mentioned in Sect. 1.1 regarding minimum requirements of 5-percentile characteristic strength, 5-percentile characteristic density and mean characteristic MOE, some additional requirements must be fulfilled when determining settings of IPs for a strength class or for a grading combination of several strength classes. These can be summarised as follows:

- At least $0.5 \%$ of the sample and not less than five pieces must be rejected.

- At least 20 pieces must be assigned to each strength class being graded.

- The minimum requirements of 5-percentile characteristic strength, 5-percentile characteristic density and mean characteristic MOE shall be fulfilled when one subsample at a time is excluded.

- Cost matrices shall be established and considered.

- A certain country check shall be performed for each country included in the sample.

- A repeatability test shall be performed of the applied IPs using at least 100 boards.

For a more detailed description of these additional requirements, see e.g. [5] and [12].

\subsection{Definitions and discussion of grade} determining properties

In [3] a comprehensive description of how the three GDPs for T-classes, i.e. $f_{\mathrm{t}, 0, \mathrm{~h}}, E_{\mathrm{t}, 0,12 \%}$ and $\rho_{12 \%}$, are determined according to standards EN 384: [2] and EN 408 [13]. Note in particular that a board's tensile strength shall be determined by destructively testing a minimum length of $9 h$ ( $h$ is the larger cross section dimension of the board) whereas the tensile MOE shall be measured over a length of $5 h$, and that these two test lengths shall include the anticipated weakest cross-section. However, if this cross-section is too close to one of the ends, it is permitted according to EN 384 [2] to test a board's second anticipated weakest cross-section. As regards the grade determining density, this shall be determined using a small sample free of knots and resin pockets cut near the fracture zone.

If the weakest cross-section of a board is not actually positioned within the tested length $(\geq 9 \mathrm{~h})$, when determining the board tensile strength, the determined corrected tensile strength, represented by 
$f_{\mathrm{t}, 0, \mathrm{~h}}$, is higher than what it would have been if the weakest cross-section had been included in the tested length. Correspondingly, a too high tensile MOE, represented by $E_{\mathrm{t}, 0,12 \%}$, is most likely obtained if the weakest cross-section is not included in the tested length.

In Table 1, new notations of corrected tensile strength and of corrected tensile MOE are now introduced. The notations $f_{\mathrm{t}, 0, \mathrm{~h} \text {,test }}$ and $E_{\mathrm{t}, 0,12 \% \text {,test }}$, are used for the GDPs that are determined in accordance with EN 384 [2] and EN 408 [13] i.e. the grade determining tensile strength and grade determining tensile MOE that up until now have been denoted $f_{\mathrm{t}, 0, \mathrm{~h}}$ and $E_{\mathrm{t}, 0,12 \%}$, respectively. The notation 'test' added in the indexing is used to highlight that these properties are valid for tested parts of boards. However, as mentioned in the previous paragraph, if the weakest cross-section of a board is not tested, the actual tensile strength and tensile MOE of the board are lower than the values achieved from the test. Therefore the notations $f_{\mathrm{t}, 0, \mathrm{~h} \text {, whole }}$ and $E_{\mathrm{t}, 0,12 \% \text {, whole }}$ are introduced to denote the corrected tensile strength and corrected tensile MOE of the very weakest section of the whole board. For any given board, $f_{\mathrm{t}, 0, \mathrm{~h} \text {, whole }} \leq f_{\mathrm{t}, 0, \mathrm{~h} \text {,test }}$ and $E_{\mathrm{t}, 0,12 \% \text {,whole }} \leq E_{\mathrm{t}, 0,12 \% \text {,est }}$, equality apply only if the weakest cross-section is anticipated correctly and included in tested length. To be very clear, it should particularly be noted that for any given board the only way to know, with certainty, that the actually weakest cross-section is tested, would be to test the entire board in the tensile test. However, of practical reasons (considerable parts of the boards are within the grips) the entire board cannot be tested. Thus, $f_{\mathrm{t}, 0, \mathrm{~h} \text {,whole }}$ and $E_{\mathrm{t}, 0,12 \% \text {, whole cannot be determined in practice since }}$ this, by definition, would require knowledge that is not available. Still, $f_{\mathrm{t}, 0, \mathrm{~h} \text {,whole }}$ and $E_{\mathrm{t}, 0,12 \% \text {,whole }}$ are necessary concepts for the following evaluation.
As regards $\rho_{12 \%}$, this density is determined using a small specimen of clear wood cut near the fracture zone (EN 408 [13]). Even though another specimen would be used for determination of clear wood density when testing another cross-section, there is no reason to assume that this would change the determined density in a significant way. Hence, no new notations of $\rho_{12 \%}$ are introduced.

\subsection{Definitions and discussion of indicating properties}

As mentioned in Sect. 1.1, there is a fundamental difference between IPs that are based solely on global board properties like mass, resonance frequency and board dimensions, see [3], Eqs. 15-16, and IPs that are based on local board properties like calculated local axial or bending MOE, see [3], Eqs. 13-14. The difference is that IPs based on local board properties may be defined to represent either the whole board or only a selected part of it, as for example the part of the board that is place between the grips in a destructive tensile test. This is important since IPs are used to predict tensile strength which can be defined either as $f_{\mathrm{t}, 0, \mathrm{~h} \text {, whole }}$ or as $f_{\mathrm{t}, 0, \mathrm{~h} \text {,test }}$, as explained in Sect. 2.1. Thus, definitions of IPs need to be further developed, before procedures for grading of boards into strength classes are presented and evaluated.

Figures 1a-b illustrate two alternative ways to define an IP for prediction of GDPs on the basis of bending MOE-profiles. Note that both figures show the same profile. If only the part of the board destructively tested is considered, the IP is defined as the lowest local bending MOE along this part of the board, see Fig. 1a. This is how $E_{\mathrm{b}, 90, \text { nom }}$ was determined in [3]. In this paper 'test' is added to the indexing to highlight that this IP represents the lowest local bending MOE of the destructivly tested part of the board, i.e.

Table 1 Definitions of applied grade determining properties

\begin{tabular}{|c|c|c|}
\hline GDP & Tested part of board ${ }^{\mathrm{a}}$ & Whole board ${ }^{\mathrm{b}}$ \\
\hline Grade determining tensile strength & $f_{\mathrm{t}, 0, \mathrm{~h}, \text { test }}\left(=f_{\mathrm{t}, 0, \mathrm{~h}}\right.$ in Part 1$)$ & $f_{\mathrm{t}, 0, \mathrm{~h}, \text { whole }}$ \\
\hline Grade determining tensile $M O E$ & $E_{\mathrm{t}, 0,12 \%, \text { test }}\left(=E_{\mathrm{t}, 0,12 \%}\right.$ in Part 1$)$ & $E_{\mathrm{t}, 0,12 \%, \text { whole }}$ \\
\hline Grade determining density & $\rho_{12 \%}$ & \\
\hline
\end{tabular}

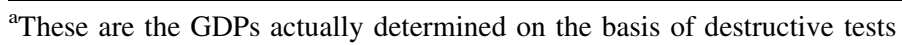

${ }^{\mathrm{b}}$ These are the GDPs aimed for but not always determined in practice 
$E_{\mathrm{b}, 90, \text { nom,test }}=E_{\mathrm{b}, 90, \text { nom }}$ ([3], Eq. 14). However, an IP can also be defined by considering the whole board's MOE-profile, i.e. as the lowest local bending MOE of the entire board, see Fig. 1b. The lowest value along the whole board's bending MOE-profile is herein denoted $E_{\mathrm{b}, 90, \text { nom,whole }}$. For the particular board represented in Fig. $1, E_{\mathrm{b}, 90 \text {,nom, whole }}<E_{\mathrm{b}, 90 \text {,nom,test }}$ since the board's weakest cross-section, as anticipated on the basis of the calculated bending MOE-profile, was not positioned within the destructively tested length. Corresponding definitions as those introduced in this paragraph can also be made for other IPs based on local board properties. For example, an IP determined on the basis of local axial MOE can, with obvious notations, be defined either as $E_{\mathrm{a}, 90, \text { nom,test }}\left(=E_{\mathrm{a}, 90, \text { nom }}\right.$, [3], Eq. 13) or as $E_{\mathrm{a}, 90, \text { nom,whole }}$.

The now available set of IPs are summarised in Table 2, only including IPs representing a single predictor variable, i.e. IPs evaluated using single regression. The column in Table 2 with heading Tested part of board includes IPs that are determined by the lowest value/property of the part of the board destructively tested, i.e. $E_{\mathrm{a}, 90, \text { nom,test }}$ and $E_{\mathrm{b}, 90, \text { nom,test }}$.
The column with heading Whole board includes IPs that are determined as the lowest local property of the entire board, i.e. $E_{\mathrm{a}, 90, \text { nom, whole }}$ and $E_{\mathrm{b}, 90 \text {,nom, whole, and }}$ IPs that represents global board properties, like $E_{\mathrm{dyn}, 12 \%}$ and $\rho_{\mathrm{s}, 12 \%}$. Thus, all IPs in this column represent, in some sense, the whole board.

As regards the IPs defined in [3] on the basis of multiple linear regression, i.e. $\mathrm{IP}_{\mathrm{E}, \mathrm{a}}$ and $\mathrm{IP}_{\mathrm{E}, \mathrm{b}}$, see Eqs. 17-18 in [3], these were derived by combining $E_{\mathrm{dyn}, 12 \%}$ with $\mathrm{E}_{\mathrm{a}, 90, \text { nom,test }}$ and $\mathrm{E}_{\mathrm{b}, 90, \text { nom,test, }}$ respectively. For prediction of tensile strength, $\operatorname{IP}_{\mathrm{E}, \mathrm{b}, \mathrm{f}, 1-}$ $=\mathrm{IP}_{\mathrm{E}, \mathrm{b}}$ was defined by the function

$I P_{\mathrm{E}, \mathrm{b}, \mathrm{f}, 1}(u, v)=k_{3, \mathrm{f}, 1}+k_{4, \mathrm{f}, 1} \cdot u+k_{5, \mathrm{f}, 1} \cdot v$

where $k_{3, \mathrm{f}, 1}, k_{4, \mathrm{f}, 1}$ and $k_{5, \mathrm{f}, 1}$ are the constants obtained for the plane best fitted to the scatter between the predictor variables $u=E_{\mathrm{b}, 90, \text { nom,test }}$ and $v=E_{\mathrm{dyn}, 12 \%}$, and the dependent variable $f_{\mathrm{t}, 0, \mathrm{~h}, \text { test }}$ by the least square method. The indexing ' $\mathrm{f}$ ' of $\mathrm{IP}_{\mathrm{E}, \mathrm{b}, \mathrm{f}, 1}$ is added to clarify that $f_{\mathrm{t}, 0, \mathrm{~h} \text {, test }}$ is used to define the function of Eq. 1 (note that the notations of constants in Eq. 1 above is consistent with the corresponding notation in Eq. 18 in [3]) and the indexing ' 1 ' of $\mathrm{IP}_{\mathrm{E}, \mathrm{b}, \mathrm{f}, 1}$ is added to
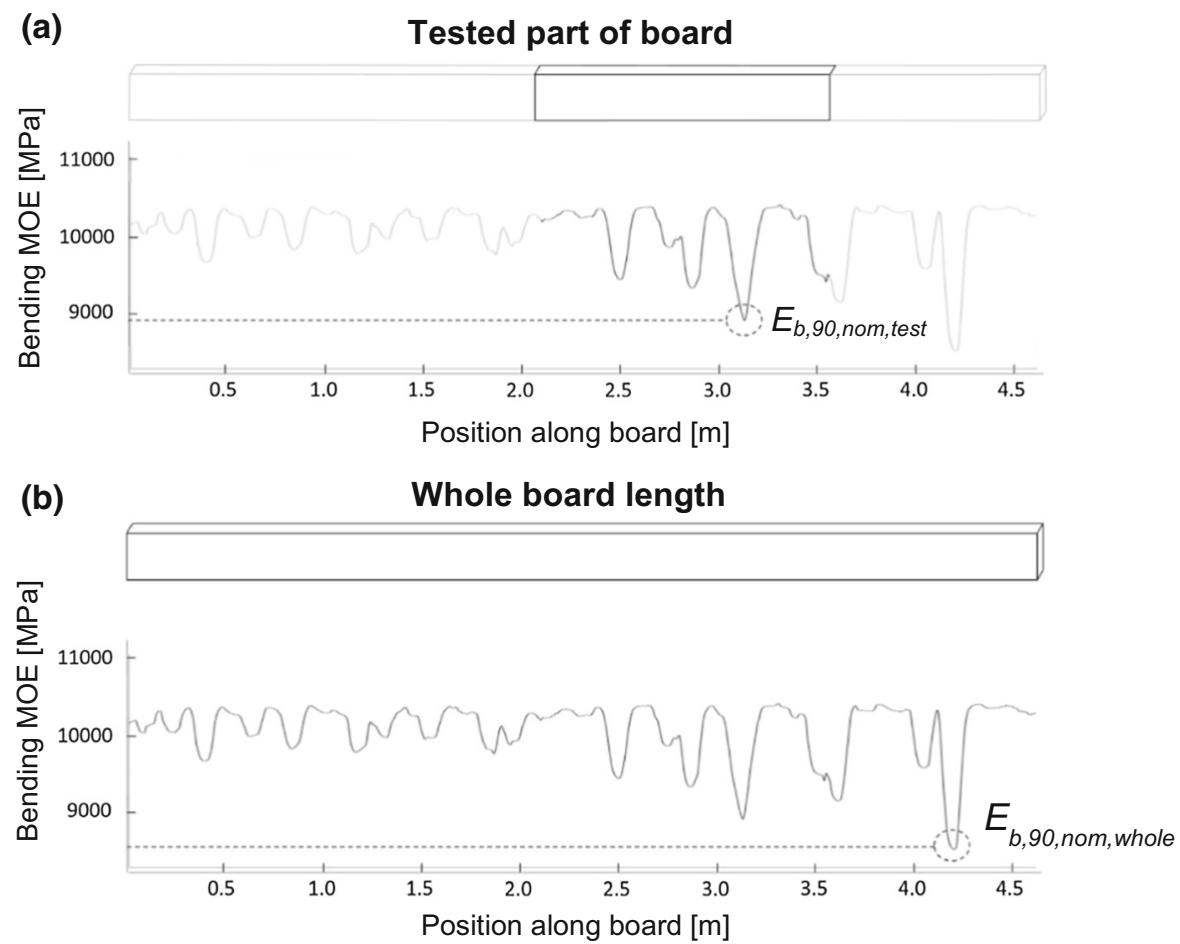

Fig. 1 IP definitions based on local fibre orientation: a $E_{b, 90, \text { nom,test }}$ defined as the lowest value of the bending MOE-profile along the destructively tested part of the board, this part represented by a solid black line. $\mathbf{b} \mathrm{E}_{\mathrm{b}, 90 \text {,nom,whole }}$ determined as the lowest value of the whole board's bending MOEprofile 
Table 2 IP definitions based on single predictor variables, representing tested part of board and whole board, respectively

\begin{tabular}{lll}
\hline Type of IP & Tested part of board & Whole board \\
\hline Board density & & $\rho_{\mathrm{s}, 12 \%}^{\mathrm{a}}$ \\
Dynamic axial MOE & & $E_{\mathrm{dyn}, 12 \%}^{\mathrm{a}}$ \\
IPs based on local fibre orientation & $E_{\mathrm{a}, 90, \text { nom,test }}\left(=E_{\mathrm{a}, 90, \text { nom in Part 1) }}\right.$ & $E_{\mathrm{a}, 90, \text { nom,whole }}^{\mathrm{b}}$ \\
& $E_{\mathrm{b}, 90, \text { nom,test }}\left(=E_{\mathrm{b}, 90, \text { nom } \text { in Part 1) }}^{\mathrm{b}}\right.$ & $E_{\mathrm{b}, 90, \text { nom,whole }}$ \\
\hline
\end{tabular}

${ }^{a}$ IP representing a global board property

${ }^{\mathrm{b}}$ IP representing a lowest value/lowest property along the entire board

distinguish the IP and the constants of Eq. 1 from another set of IP and constants introduced in Eq. 2, below. Now, $f_{\mathrm{t}, 0, \mathrm{~h}, \text { test }}$ for a board can be predicted by inserting values of $E_{\mathrm{b}, 90, \text { nom,test }}$ and $E_{\mathrm{dyn}, 12 \%}$ as variables $u$ and $v$, respectively, in Eq. 1 . Note that Eq. 1 can also be used for prediction of $f_{\mathrm{t}, 0, \mathrm{~h} \text {, whole }}$ of the board by inserting $E_{\mathrm{b}, 90, \text { nom, whole }}$ and $E_{\mathrm{dyn}, 12 \%}$ as variables $u$ and $v$, respectively.

Multiple linear regression can also, as an alternative, be performed using $E_{\mathrm{b}, 90, \text { nom, whole }}$ in combination with $E_{\mathrm{dyn}, 12 \%}$ to obtain the constants of the regression model. The function for this IP then reads

$I P_{\mathrm{E}, \mathrm{b}, \mathrm{f}, 2}(u, v)=k_{3, \mathrm{f}, 2}+k_{4, \mathrm{f}, 2} \cdot u+k_{5, \mathrm{f}, 2} \cdot v$

where $k_{3, \mathrm{f}, 2}, k_{4, \mathrm{f}, 2}$ and $k_{5, \mathrm{f}, 2}$ are the constants that define the planes best fitted to the scatter between the predictor variables $E_{\mathrm{b}, 90, \text { nom,whole }}$ and $E_{\mathrm{dyn}, 12 \%}$, and the dependent variable $f_{\mathrm{t}, 0 \text {, h,test }}$ by the least square method. Consequently, by inserting board values of $E_{\mathrm{b}, 90, \text { nom,whole }}$ and $E_{\mathrm{dyn}, 12 \%}$ as $u$ and $v$, respectivly, in Eq. 2 means that $\mathrm{IP}_{\mathrm{E}, \mathrm{b}, \mathrm{f}, 2}$ gives a prediction of $f_{\mathrm{t}, 0, \mathrm{~h} \text {,test }}$ of the board. Note, however, that application of Eq. 2, in contrast to application of Eq. 1, does not enable prediction of $f_{\mathrm{t}, 0, \mathrm{~h} \text {,whole. IPs, predictor variables and }}$ predictions of tensile strength, corresponding to Eqs. 1-2, are summarised in Table 3.

\subsection{Models applied for calculation of settings and yield}

The procedure for determination of settings and yield for strength classes consists firstly of deriving settings in accordance with EN 14081-2 [7] and, secondly, by applying these settings to grade each board and calculate the corresponding yield. Using the definitions given in Sects. 2.1-2.2, two different procedures/models for determination of settings and yield for IPs based on a local board property are now introduced. Below these are referred to as Model 1 and Model 2. Included in these models are only a selection of the IPs defined above and in [3], namely the IPs given in Table 3 , and $E_{\mathrm{dyn}, 12 \%}$ and $\rho_{\mathrm{s}, 12 \%}$.

\subsubsection{Strength}

Boards assigned to a certain T-class must, as explained above, have a $f_{\mathrm{t}, 0, \mathrm{k}}$ exceeding the minimum requirement of characteristic strength given in EN 338 [1]. This means that at least $95 \%$ of the assigned boards must have higher tensile strength than the characteristic tensile strength of the graded class.

In Model 1, settings for strength are determined for $\operatorname{IP}_{\mathrm{E}, \mathrm{b}, \mathrm{f}, 1}\left(E_{\mathrm{b}, 90, \text { nom,test }}, \quad E_{\mathrm{dyn}, 12 \%}\right)$, such that $f_{\mathrm{t}, 0, \mathrm{k}}$,

Table 3 IP definitions based on two predictor variables, representing tested part of a board and the whole board, respectively

\begin{tabular}{|c|c|c|c|}
\hline IP & Function & Prediction of $f_{\mathrm{t}, 0, \mathrm{~h}, \mathrm{test}}$ & Prediction of $f_{\mathrm{t}, 0, \mathrm{~h}, \text { whole }}$ \\
\hline \multirow[t]{2}{*}{ IPs based on two predictor variables } & $\operatorname{IP}_{\mathrm{E}, \mathrm{b}, \mathrm{f}, 1}(u, v)^{\mathrm{a}}$ & $\begin{array}{l}u=E_{\mathrm{b}, 90, \text { nom,test }} \\
v=E_{\mathrm{dyn}, 12 \%}\end{array}$ & $\begin{array}{l}u=E_{\mathrm{b}, 90, \text { nom }, \text { whole }} \\
v=E_{\mathrm{dyn}, 12 \%}\end{array}$ \\
\hline & $\operatorname{IP}_{\mathrm{E}, \mathrm{b}, \mathrm{f}, 2}(u, v)^{\mathrm{b}}$ & $\begin{array}{l}u=E_{\mathrm{b}, 90, \text { nom }, \text { whole }} \\
v=E_{\mathrm{dyn}, 12 \%}\end{array}$ & - \\
\hline
\end{tabular}

${ }^{\mathrm{a}}$ Constants of the function of Eq. 1, i.e. $k_{3, \mathrm{f}, 1}, k_{4, \mathrm{f}, 1}$ and $k_{5, \mathrm{f}, 1}$, are determined with $u=E_{\mathrm{b}, 90 \text {,nom,test }}$

${ }^{\mathrm{b}}$ Constants of the function of Eq. 2, i.e. $k_{3, \mathrm{f}, 2}, k_{4, \mathrm{f}, 2}$ and $k_{5, \mathrm{f}, 2}$, are determined with $u=E_{\mathrm{b}, 90 \text {,nom, whole }}$ 
calculated by means of $f_{\mathrm{t}, 0, \mathrm{~h}, \text { test }}$, of assigned boards exceeds the minimum requirement of 5-percentile characteristic strength and all additional requirements given in EN 14081-2 [7] (see Sect. 2) are fulfilled. The actual grading is then performed such that the entire length of the boards are graded, i.e. the grading is carried out by predicting $f_{\mathrm{t}, 0, \mathrm{~h} \text {, whole }}$ using $\mathrm{IP}_{\mathrm{E}, \mathrm{b}, \mathrm{f}, 1}(-$ $\left.E_{\mathrm{b}, 90, \text { nom,whole }}, E_{\mathrm{dyn}, 12 \%}\right)$. If a board's $\operatorname{IP}_{\mathrm{E}, \mathrm{b}, \mathrm{f}, 1}(-$ $\left.E_{\mathrm{b}, 90, \text { nom,whole }}, E_{\mathrm{dyn}, 12 \%}\right)$ then exceeds the setting for the IP of the graded class, and if the board's IPs applied for density and MOE, respectively, also exceed their corresponding settings, the board is assigned to the graded class.

In Model 2, settings for strength are determined for $\mathrm{IP}_{E, b, f, 2}\left(E_{\mathrm{b}, 90, \text { nom, whole }}, E_{\mathrm{dyn}, 12 \%}\right)$, such that $f_{\mathrm{t}, 0, \mathrm{k}}$, calculated by means of $f_{\mathrm{t}, 0, \mathrm{~h}, \mathrm{test}}$, of assigned boards exceeds the minimum requirement of 5-percentile characteristic strength and all additional requirements given in EN 14081-2 [7] are fulfilled. The grading with respect to strength is then carried out using the same IPs, i.e. by predicting $f_{\mathrm{t}, 0, \mathrm{~h}, \text { test }}$ by $\operatorname{IP}_{E, b, f, 2}\left(E_{\mathrm{b}, 90 \text {,nom, whole }}\right.$, $\left.E_{\mathrm{dyn}, 12 \%}\right)$. Note that this model/procedure corresponds to the procedure employed when grading boards on the basis of an IP that simply represents a global board property, like $E_{\mathrm{dyn}, 12 \%}$.

\subsubsection{Density}

To fulfil the density requirement of a T-class, at least $95 \%$ of the assigned board must have a higher density than the 5-percentile characteristic density of the graded class. In both Model 1 and Model 2, settings for density are determined for the IP $\rho_{\mathrm{s}, 12 \%}$ such the minimum requirement of 5-percentile characteristic density and all additional requirements given in $\mathrm{EN}$ 14081-2 [7] of assigned board are fulfilled. The actual grading of boards is then done using the same IP.

\subsubsection{MOE}

To fulfil the requirement of MOE of a T-class, the mean characteristic MOE, i.e. $E_{\mathrm{t}, 0 \text {,mean }}$ of assigned boards, must be higher than the requirement of mean characteristic MOE given in EN 338 [1] of the graded class divided by 0.95 . In both Model 1 and Model 2, settings for MOE are determined for the IP $E_{\mathrm{dyn}, 12 \%}$ such that the requirement of mean characteristic MOE and all additional requirements given in EN 14081-2
[7] of assigned board are fulfilled. Grading of boards is then done using the same IP.

Table 4 gives a compilation of the IPs used in Model 1 and Model 2.

\subsubsection{Procedure to meet requirements of all GDPs}

The procedure of fulfilling the minimum requirements of 5-percentile characteristic strength, 5-percentile characteristic density and mean characteristic MOE of the sample of boards used to determine settings is an iterative process; first, all the boards in the investigated total sample are ranked for one of the GPDs and the boards that do not fulfil the requirement of that property are excluded; second, using only the boards fulfilling the requirements of the previously investigated GPD, the ranking and exclusion procedure is repeated for the next GPD; third, the procedure is repeated for the last GPD. Settings for IPs can, thus, differ slightly dependent on the order applied. In this study the following order was used: (1) strength, (2) density and (3) MOE.

\section{Results and analysis}

As explained in [3], the non-destructive measurements (except dynamic excitation) necessary for calculating IPs, were carried out both before and after planing the boards. Results of the two grading procedures presented herein (Model 1 and Model 2) and the IPs involved regarding strength are thus evaluated both for boards with sawn and planed surfaces.

\subsection{Selection of critical sections and tested parts of boards}

The visual inspection carried out to identify each board's weakest testable cross-section was performed manually by a trained operator at an accredited testing institute (making an overall assessment of size and location of knots, etcetera) and resulted in that a certain part of each board was placed between the grips in the testing machine. The tested length between the grips (sum of all boards) was $30.2 \%$ of the total length of all 967 boards. If the operator's assessment of each board's position of weakest testable crosssection had agreed perfectly with the position of the weakest testable cross-section as indicated by the 
Table 4 IPs and GPDs used in Model 1 and Model 2 for determination of settings and grading of boards
${ }^{\mathrm{a}}$ GDPs used for calculation of $f_{\mathrm{t}, 0, \mathrm{k}}, \rho_{\mathrm{k}}$ and $E_{\mathrm{t}, 0 \text {,mean }}$ when deriving settings

\begin{tabular}{|c|c|c|c|}
\hline & \multicolumn{2}{|l|}{ Settings calculations } & \multirow{2}{*}{$\begin{array}{l}\text { Grading } \\
\text { IPs }\end{array}$} \\
\hline & IPs & $\mathrm{GDPs}^{\mathrm{a}}$ & \\
\hline \multicolumn{4}{|l|}{ Model 1} \\
\hline Strength & $\operatorname{IP}_{\mathrm{E}, \mathrm{b}, \mathrm{f}, 1}\left(E_{b, 90, \text { nom,test }}, E_{\mathrm{dyn}, 12 \%}\right)$ & $f_{\mathrm{t}, 0, \mathrm{~h}, \mathrm{test}}$ & $\operatorname{IP}_{\mathrm{E}, \mathrm{b}, \mathrm{f}, 1}\left(E_{b, 90, \text { nom,whole }}, E_{\mathrm{dyn}, 12 \%}\right)$ \\
\hline Density & $\rho_{\mathrm{s}, 12 \%}$ & $\rho_{12 \%}$ & $\rho_{\mathrm{s}, 12 \%}$ \\
\hline Stiffness & $E_{\mathrm{dyn}, 12 \%}$ & $E_{\mathrm{t}, 0,12 \%, \text { test }}$ & $E_{\mathrm{dyn}, 12 \%}$ \\
\hline \multicolumn{4}{|l|}{ Model 2} \\
\hline Strength & $\operatorname{IP}_{\mathrm{E}, \mathrm{b}, \mathrm{f}, 2}\left(E_{b, 90, \text { nom,whole }}, E_{\mathrm{dyn}, 12 \%}\right)$ & $f_{\mathrm{t}, 0, \mathrm{~h}, \mathrm{test}}$ & $\operatorname{IP}_{\mathrm{E}, \mathrm{b}, \mathrm{f}, 2}\left(E_{b, 90, \text { nom, whole }}, E_{\mathrm{dyn}, 12 \%}\right)$ \\
\hline Density & $\rho_{\mathrm{s}, 12 \%}$ & $\rho_{12 \%}$ & $\rho_{\mathrm{s}, 12 \%}$ \\
\hline Stiffness & $E_{\mathrm{dyn}, 12 \%}$ & $E_{\mathrm{t}, 0,12 \%, \text { test }}$ & $E_{\mathrm{dyn}, 12 \%}$ \\
\hline
\end{tabular}

lowest calculated bending MOE, $50.9 \%$ (profiles valid for un-planed boards) and 53.3\% (profiles valid for planed boards) of thus indicated cross-sections would have been placed between the grips. However, when boards were positioned as decided by the operator, the weakest testable cross-section as indicated by the calculated bending MOE-profiles were placed between the grips in only $31.1 \%$ (profiles valid for un-planed boards) and $32.4 \%$ (profiles valid for planed boards) of the cases. Note that the expected, corresponding percentage, if boards were randomly placed into the testing machine would be $30.2 \%$. This indicates a very weak relationship between what cross-sections/positions that were decided by the operator to be tested and the weakest cross-sections/positions as indicated by the calculated bending MOE-profiles.

\subsection{Accuracy of prediction of tensile strength}

The scatter between $\operatorname{IP}_{\mathrm{E}, \mathrm{b}, \mathrm{f}, 1}\left(E_{\mathrm{b}, 90, \text { nom,test }}, E_{\mathrm{dyn}, 12 \%}\right)$, calculated on the basis of non-destructive measurement results obtained after planing, and $f_{\mathrm{t}, 0, \mathrm{~h}, \text { test }}$ is exhibited in Fig. 2a. The corresponding scatter for the indicating property $\operatorname{IP}_{\mathrm{E}, \mathrm{b}, \mathrm{f}, 2}\left(E_{\mathrm{b}, 90 \text {,nom, whole }}, E_{\mathrm{dyn}, 12 \%}\right)$ is shown in Fig. 2b. The mathematical expressions of $\mathrm{IP}_{\mathrm{E}, \mathrm{b}, \mathrm{f}, 1}$ and $\mathrm{IP}_{\mathrm{E}, \mathrm{b}, \mathrm{f}, 2}$ are shown on the $\mathrm{x}$-axes in respective figure. Plotted in each figure is also respective scatter's coefficient of determination $\left(r^{2}\right)$, SEE, calculated on the basis of linear regression, and regression line.

In Fig. 2a, b it is shown that the IP used for derivation of settings in Model 1, i.e. $\operatorname{IP}_{\mathrm{E}, \mathrm{b}, \mathrm{f}, 1}(-$ $\left.E_{\mathrm{b}, 90, \text { nom,test }}, E_{\mathrm{dyn}, 12 \%}\right)$, results in a higher $r^{2}$ and a lower SEE to $f_{\mathrm{t}, 0, \mathrm{~h}, \text { test }}$ than what $\operatorname{IP}_{\mathrm{E}, \mathrm{b}, \mathrm{f}, 2}\left(E_{\mathrm{b}, 90 \text {,nom, whole, }}\right.$

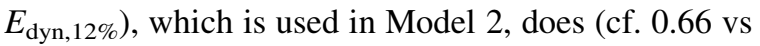

0.61, and 6.79 MPa vs 7.33 MPa, respectivetly). This is not very surprising since the varible $E_{\mathrm{b}, 90 \text {,nom,test }}$, which was applied in the evaluation of $\operatorname{IP}_{\mathrm{E}, \mathrm{b}, \mathrm{f}, 1}(-$ $\left.E_{\mathrm{b}, 90 \text {,nom,test }}, E_{\mathrm{dyn}, 12 \%}\right)$, represents the weakest crosssection of the destructivly tested part of the board,

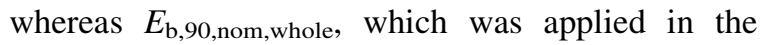
evaluation of $\operatorname{IP}_{\mathrm{E}, \mathrm{b}, \mathrm{f}, 2}\left(E_{\mathrm{b}, 90 \text {,nom, whole, }} E_{\mathrm{dyn}, 12 \%}\right)$, represents the weakest cross-section of the entire board. A corresponding observation was made in [6].

A compilation of coefficients of determination and SEEs for scatters between $\operatorname{IP}_{\mathrm{E}, \mathrm{b}, \mathrm{f}, 1}\left(E_{\mathrm{b}, 90 \text {,nom,test }}\right.$, $\left.E_{\mathrm{dyn}, 12 \%}\right)$ and $f_{0, h, \text { test }}$, and between $\operatorname{IP}_{\mathrm{E}, \mathrm{b}, \mathrm{f}, 2}(-$ $\left.E_{\mathrm{b}, 90, \text { nom,whole }}, E_{\mathrm{dyn}, 12 \%}\right)$ and $f_{0, h, t e s t}$, both before and after planing, is given in Table 5. Included in this table is also the coefficients of determination and SEEs obtained with non-linear regression using a second order polynomial. The differences in $r^{2}$ and SEE, respectively, using non-linear rather than linear regression, is larger for $\operatorname{IP}_{\mathrm{E}, \mathrm{b}, \mathrm{f}, 1}\left(E_{\mathrm{b}, 90, \text { nom,test }}, E_{\mathrm{dyn}, 12 \%}\right)$ than what it is for $\operatorname{IP}_{\mathrm{E}, \mathrm{b}, \mathrm{f}, 2}\left(E_{\mathrm{b}, 90, \text { nom,whole }}, E_{\mathrm{dyn}, 12 \%}\right)$. For $\operatorname{IP}_{\mathrm{E}, \mathrm{b}, \mathrm{f}, 1}\left(E_{\mathrm{b}, 90, \text { nom,test }}, E_{\mathrm{dyn}, 12 \%}\right)$, an $r^{2}$ as high as 0.70 was obtained for $f_{t, O, h, t e s t}$.

\subsection{Yield in T-classes}

Calculated yield for Model 1 and Model 2, respectively, is given in Table 6 (single grades) and Table 7 (grading combinations). For comparison, Table 6 also includes the yield obtained when the settings determined using Model 1 were applied to grade only the part of the boards destructively tested. The latter is referred to as Model 1-grading of test length. Moreover, Tables 6 and 7 include calculated yields for a grading method applying $E_{\mathrm{dyn}, 12 \%}$ as IP to both tensile strength and MOE, and $\rho_{s, 12 \%}$ as IP to density. This method, herein referred to as Dynamic MOE 

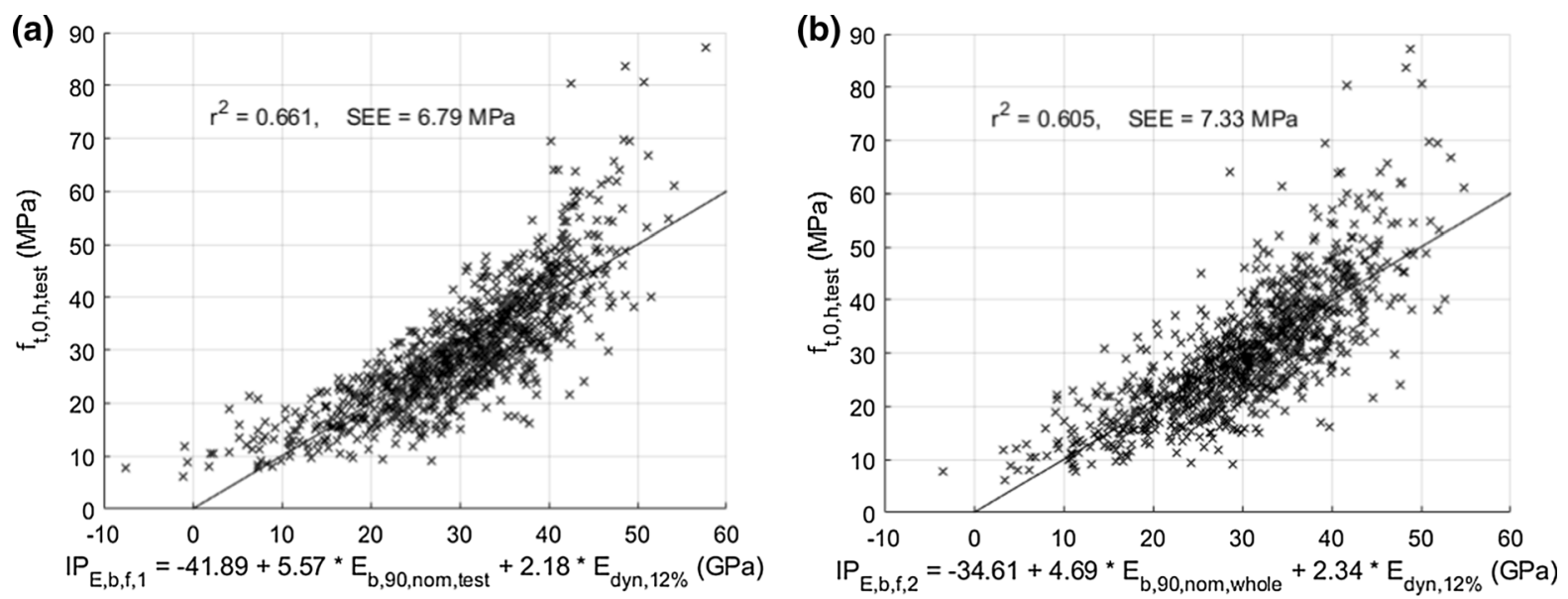

Fig. 2 a Scatter between $\operatorname{IP}_{\mathrm{E}, \mathrm{b}, \mathrm{f}, 1}\left(E_{\mathrm{b}, 90, \text { nom,test }}, \mathrm{E}_{\mathrm{dyn}, 12 \%}\right)$ and $\mathrm{f}_{\mathrm{t}, 0, \mathrm{~h}, \text { test }}$ after planing, and $\mathbf{b}$ scatter between $\operatorname{IP}_{\mathrm{E}, \mathrm{b}, \mathrm{f}, 2}\left(E_{\mathrm{b}, 90, \text { nom,whole, }}\right.$ $\left.E_{\text {dyn, } 12 \%}\right)$ and $\mathrm{f}_{\mathrm{t}, 0, \mathrm{~h}, \text { test }}$ after planing

Table 5 Coefficients of determination and SEEs for $\mathrm{f}_{\mathrm{t}, 0, \mathrm{~h}, \mathrm{test}}$

\begin{tabular}{|c|c|c|c|c|c|c|c|c|}
\hline & \multicolumn{4}{|c|}{$\operatorname{IP}_{\mathrm{E}, \mathrm{b}, \mathrm{f}, 1}\left(E_{\mathrm{b}, 90, \text { nom,test }}, E_{\mathrm{dyn}, 12 \%}\right)$} & \multicolumn{4}{|c|}{$\operatorname{IP}_{\mathrm{E}, \mathrm{b}, \mathrm{f}, 2}\left(E_{\mathrm{b}, 90, \text { nom,whole }}, E_{\mathrm{dyn}, 12 \%}\right)$} \\
\hline & \multicolumn{2}{|c|}{ Linear } & \multicolumn{2}{|c|}{ Non-linear ${ }^{\mathrm{a}}$} & \multicolumn{2}{|c|}{ Linear } & \multicolumn{2}{|c|}{ Non-linear ${ }^{\mathrm{a}}$} \\
\hline & $\mathrm{r}^{2}$ & SEE (MPa) & $r^{2}$ & SEE (MPa) & $\mathrm{r}^{2}$ & SEE (MPa) & $r^{2}$ & SEE (MPa) \\
\hline Sawn & 0.65 & 6.93 & 0.68 & 6.64 & 0.60 & 7.38 & 0.61 & 7.26 \\
\hline Planed & 0.66 & 6.79 & 0.70 & 6.42 & 0.61 & 7.33 & 0.62 & 7.17 \\
\hline
\end{tabular}

${ }^{\mathrm{a}} \mathrm{Second}$ order polynomials were used for the non-linear regressions

grading, is employed in several grading machines on the market. Included in Tables 6 and 7 are also the percentage of boards in the Optimum grade, i.e. the highest grade a board can be assigned to such that the minimum requirements of 5-percentile characteristic strength, 5-percentile characteristic density and mean characteristic MOE are met. The yields presented in Tables 6 and 7, and the settings used for the presented grades and grading combinations, were calculated using all 967 boards. Calculations were performed such that the largest possible yield was obtained for the highest grade class, i.e. no optimisation was performed to minimise the number of rejects. As regards settings of strength classes, for T12-T22 the yield of Model 1 and Model 2 was determined using settings of grade determining tensile strength alone i.e. for these classes no settings had to be set for grade determining density and grade determining tensile MOE since the requirements on these were already fulfilled. Furthermore, for class T26 the yield was determined by settings on both grade determining tensile strength and grade determining density, and for class T30 the yield was determined by settings on all three GDPs.

Compared to the grading method Dynamic MOE grading, both Model 1 and Model 2 resulted in larger yields for higher grades, see Table 6 and 7. The grading method Dynamic MOE grading could not be applied to determine settings for the class T30 since the number of assigned pieces to this grade were too few, see Sect. 2.

For single grades T22 and higher (Table 6), and for all highest grade in double grades (Table 7), higher yield was achieved using Model 2 than using Model 1 . In fact, for the single grades T22 and T26, and using IPs calculated by means of measurement results obtained when the boards had a sawn surface finish, Model 2 resulted in yields that were roughly 7-8 percentage higher, after fulfilling the requirement of country check, than what the yields achieved using Model 1 were, see Table 6. Using IPs calculated by 
Table 6 Calculated yield for single grades

\begin{tabular}{|c|c|c|c|c|c|}
\hline Grade & Model $1(\%)$ & $\begin{array}{l}\text { Model } 1 \text {-grading } \\
\text { of test length }(\%)\end{array}$ & Model $2(\%)$ & $\begin{array}{l}\text { Dynamic MOE } \\
\text { grading }(\%)\end{array}$ & $\begin{array}{l}\text { Optimum } \\
\text { grade }(\%)\end{array}$ \\
\hline \multicolumn{6}{|l|}{ Sawn } \\
\hline $\mathrm{T} 12$ & 99.1 & 99.5 & 99.5 & 99.5 & 100.0 \\
\hline T15 & $95.6^{\mathrm{FIN}}(96.2)$ & $96.1^{\text {FIN }}(97.5)$ & $95.8^{\mathrm{FIN}+\mathrm{NOR}}(97.7)$ & $94.5^{\mathrm{FIN}}(97.8)$ & 98.2 \\
\hline T18 & 72.3 & 80.0 & 78.3 & 71.6 & 90.4 \\
\hline $\mathrm{T} 22$ & 51.8 & $61.8^{\mathrm{FIN}}(63.0)$ & $59.6^{\mathrm{FIN}}(60.6)$ & $40.8^{\mathrm{FIN}}(41.7)$ & 79.7 \\
\hline $\mathrm{T} 26$ & 26.3 & 37.6 & 33.2 & 19.2 & 59.9 \\
\hline $\mathrm{T} 30$ & 14.1 & 22.0 & 14.9 & - & 31.7 \\
\hline \multicolumn{6}{|l|}{ Planed } \\
\hline T12 & 99.2 & 99.5 & 99.5 & 99.5 & 100.0 \\
\hline T15 & 96.1 & $96.1^{\text {FIN }}(97.4)$ & $96.3^{\mathrm{FIN}+\mathrm{NOR}}(97.6)$ & $95.5^{\mathrm{FIN}+\mathrm{NOR}}(97.8)$ & 98.2 \\
\hline T18 & 76.5 & $83.4^{\mathrm{FIN}}(83.6)$ & $79.8^{\mathrm{FIN}}(80.1)$ & 70.9 & 90.4 \\
\hline $\mathrm{T} 22$ & 53.5 & $62.6^{\mathrm{FIN}}(65.3)$ & $59.4^{\mathrm{FIN}}(61.5)$ & $42.9^{\mathrm{FIN}}(43.3)$ & 79.7 \\
\hline $\mathrm{T} 26$ & 28.6 & 39.8 & 33.5 & $15.9^{\mathrm{NOR}}(17.9)$ & 59.9 \\
\hline T30 & 13.5 & 21.9 & 14.2 & - & 31.7 \\
\hline
\end{tabular}

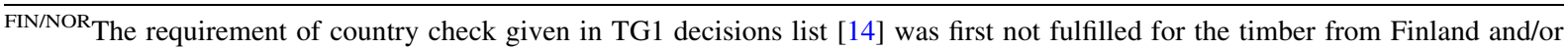
Norway but settings were adjusted such that this requirement was fulfilled. The yield obtained disregarding this requirement is given within parenthesis

Table 7 Calculated yield for different grading combinations

\begin{tabular}{|c|c|c|c|c|}
\hline Grade & Model $1(\%)$ & Model $2(\%)$ & Dynamic MOE grading (\%) & Optimum grade $(\%)$ \\
\hline \multicolumn{5}{|l|}{ Sawn } \\
\hline $\mathrm{T} 30+\mathrm{T} 12$ & $8.0+91.1$ & $8.3+91.2$ & - & $31.7+68.1$ \\
\hline $\mathrm{T} 26+\mathrm{T} 15$ & $26.3+64.6$ & $33.2+60.0^{\mathrm{FIN}}(60.4)$ & $19.2+72.8^{\mathrm{FIN}}(77.0)$ & $59.9+28.6$ \\
\hline $\mathrm{T} 22+\mathrm{T} 15$ & $51.8+23.7$ & $59.6^{\text {FIN }}(60.6)+19.8$ & $40.8^{\mathrm{FIN}}(41.7)+43.3^{\mathrm{FIN}}(43.7)$ & $79.7+9.3$ \\
\hline $\mathrm{T} 22+\mathrm{T} 14$ & $51.8+35.8$ & $59.6^{\mathrm{FIN}}(60.6)+30.1$ & $40.8^{\mathrm{FIN}}(41.7)+51.7^{\mathrm{FIN}}(53.4)$ & $79.7+12.2$ \\
\hline \multicolumn{5}{|l|}{ Planed } \\
\hline $\mathrm{T} 30+\mathrm{T} 12$ & $7.1+92.0$ & $8.6+90.9$ & - & $31.7+68.1$ \\
\hline $\mathrm{T} 26+\mathrm{T} 15$ & $28.6+61.5$ & $33.5+58.0^{\mathrm{FIN}}(60.1)$ & $15.9^{\mathrm{NOR}}(17.9)+76.2^{\mathrm{FIN}}(78.8)$ & $59.9+28.6$ \\
\hline $\mathrm{T} 22+\mathrm{T} 15$ & $53.5+21.2$ & $59.4^{\mathrm{FIN}}(61.5)+16.4$ & $42.9^{\mathrm{FIN}}(43.3)+39.4^{\mathrm{FIN}}(41.7)$ & $79.7+9.3$ \\
\hline $\mathrm{T} 22+\mathrm{T} 14$ & $53.5+33.0$ & $59.4^{\mathrm{FIN}}(61.5)+29.9$ & $42.9^{\mathrm{FIN}}(43.3)+48.4^{\mathrm{FIN}}(51.9)$ & $79.7+12.2$ \\
\hline
\end{tabular}

FIN/NOR The requirement of country check given in TG1 decisions list [14] was first not fulfilled for the timber from Finland and/or Norway but settings were adjusted such that this requirement was fulfilled. The yield obtained disregarding this requirement is given within parenthesis

means of measurement results obtained after planing, Model 2 resulted in yields in grades T22 and T26 that were approximately 5-6 percentage higher compared to the yields achieved using Model 1. Remember that the IP applied in Model 1 for prediction of $f_{t, 0, h, \text { test }}$ resulted in higher $r^{2}$ and lower standard SEE than what the IP applied for $f_{t, 0, h, t e s t}$ in Model 2 did. Even so, Model 2 gives higher yields than what Model 1 does. This is further discussed in Sect. 4.

As regards the grading combinations presented in Table 7, it is notable that the combination T22/T15, which is commonly used in Sweden, results in 
Table 8 Calculated adjustment of IP-settings for Model 1-grading of test length and Model 2, respectively, that would be needed to decrease the yield using these models to the same yields as of Model 1

\begin{tabular}{|c|c|c|c|c|}
\hline \multirow[t]{2}{*}{ Grade } & \multicolumn{2}{|c|}{$\begin{array}{l}\text { Adjustment (increase) of setting for } \mathrm{IP}_{\mathrm{E}, \mathrm{b}, \mathrm{f}, \mathrm{t}} \text { to decrease the yield } \\
\text { of Model } 1 \text {-grading of test length to same as for Model } 1\end{array}$} & \multicolumn{2}{|c|}{$\begin{array}{l}\text { Adjustment (increase) of setting for } \mathrm{IP}_{\mathrm{E}, \mathrm{b}, \mathrm{f}, 2} \text { to decrease } \\
\text { the yield of Model } 2 \text { to the same as for Model } 1\end{array}$} \\
\hline & $\mathrm{IP}_{\mathrm{E}, \mathrm{b}, \mathrm{f}, 1}(\mathrm{MPa})$ & $\operatorname{IP}_{\mathrm{E}, \mathrm{b}, \mathrm{f}, 1}(\%)$ & $\operatorname{IP}_{\mathrm{E}, \mathrm{b}, \mathrm{f}, 2}(\mathrm{MPa})$ & $\operatorname{IP}_{\mathrm{E}, \mathrm{b}, \mathrm{f}, 2}(\%)$ \\
\hline \multicolumn{5}{|l|}{ Sawn } \\
\hline $\mathrm{T} 12$ & $2.8 \rightarrow 5.7(+2.9)$ & 101 & $5.3 \rightarrow 7.1(+1.8)$ & 34 \\
\hline T15 & $11.9 \rightarrow 12.7(+0.8)$ & 6 & $13.2 \rightarrow 13.8(+1.6)$ & 4 \\
\hline $\mathrm{T} 18$ & $22.7 \rightarrow 25.6(+2.9)$ & 13 & $23.8 \rightarrow 25.5(+1.7)$ & 7 \\
\hline $\mathrm{T} 22$ & $28.4 \rightarrow 30.9(+2.5)$ & 9 & $28.8 \rightarrow 30.6(+1.8)$ & 6 \\
\hline $\mathrm{T} 26$ & $33.9 \rightarrow 36.6(+2.7)$ & 8 & $34.5 \rightarrow 36.3(+1.8)$ & 5 \\
\hline $\mathrm{T} 30$ & $37.5 \rightarrow 40.0(+2.5)$ & 7 & $39.5 \rightarrow 40.0(+0.5)$ & 1 \\
\hline \multicolumn{5}{|c|}{ Planed } \\
\hline $\mathrm{T} 12$ & $1.9 \rightarrow 4.2(+2.3)$ & 120 & $4.7 \rightarrow 6.3(+1.6)$ & 33 \\
\hline T15 & $11.3 \rightarrow 12.1(+0.8)$ & 7 & $11.7 \rightarrow 12.1(+0.4)$ & 4 \\
\hline $\mathrm{T} 18$ & $21.8 \rightarrow 24.5(+2.7)$ & 12 & $23.4 \rightarrow 24.4(+1.0)$ & 5 \\
\hline $\mathrm{T} 22$ & $28.3 \rightarrow 30.9(+2.6)$ & 8 & $28.9 \rightarrow 30.3(+1.4)$ & 5 \\
\hline $\mathrm{T} 26$ & $33.4 \rightarrow 36.0(+2.6)$ & 8 & $34.5 \rightarrow 36.3(+1.8)$ & 4 \\
\hline $\mathrm{T} 30$ & $37.8 \rightarrow 40.3(+2.5)$ & 7 & $39.5 \rightarrow 40.0(+0.5)$ & 1 \\
\hline
\end{tabular}

percentage of rejects as high as about 25\% (Model 1). A more effective grading combination is T22/T14 giving only about half the number of rejects.

The yield obtained by Model 1-grading of test length was considerably higher than the yield obtained when the full length of the boards were graded using Model 1, see Table 6. Of course, this is not surprising since the weakest cross-section, as indicated by calculated bending MOE-profiles, were placed between the grips in the testing machine in only about one-third of all destructive tests, as explained in Sect. 3.1.

In order to decrease the yield of Model 1-grading of test length and of Model 2, respectively, such that the yields obtained using these models would be the same as the yields obtained using Model 1, the settings of $\mathrm{IP}_{\mathrm{E}, \mathrm{b}, \mathrm{f}, 1}$ and $\mathrm{IP}_{\mathrm{E}, \mathrm{b}, \mathrm{f}, 2}$, respectively, would have to be increased as shown in Table 8. These figures are relevant since Model 1 is the only one out of the tree models that grades, appropriately, the boards with

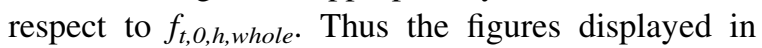
Table 8 give some basis for a discussion of correction factors to possibly apply on some grading methods/models, see Sect. 4.

\section{Discussion}

\subsection{Selection of critical sections}

According to the standard EN 384 [2] it is permitted to test a board's second weakest cross-section, if the weakest/critical cross-section is located outside the testable length. Furthermore, the weakest (or second weakest) cross-section can, as it was in this investigation, be determined by manual visual examination of the board's surfaces. However, a human can only observe and estimate the influence of visual properties such as size and location of knots when examining a board. Other properties with influence on strength, such as fibre direction, compression wood etcetera, cannot be properly taken into account. Therefore, it is very uncertain if the anticipated weakest testable cross-section actually is the weakest one, even if a trained human operator thoroughly examine each piece to decide the cross-section to be tested. In addition, skill and dedication to the task may differ between operators. Results presented herein show a very weak, or even non-existent, relationship between the weakest cross section identified by visual examination by human operator and the weakest cross 
section identified on the basis of a calculated bending MOE-profile. It is not certain, of course, that the cross section identified by means of a calculated bending MOE-profile actually is the weakest one but the point here is the remarkable lack of consistency between anticipated weakest cross sections determined by an operator and a machine grading method, respectively. This reveals an issue related to EN 384 [2] regarding the cross section to be tested since the tested part of the board will not, with reasonable certainty, include the actually weakest testable cross section. An alternative test procedure would be to simply test a random part of the board. This is how corresponding tests are performed in e.g. Australia (see [9]) and in contrast to testing performed according to EN 408 [13] this would allow for an unbiased correction of strength with respect to length effects.

\subsection{Comparison of grading models and needs for corrections}

If the weakest cross-section is not evaluated in the destructive test, the grade determining strength, i.e. $f_{t, O, h, \text { test }}$, only applies for the weakest cross-section of the tested part of the board. Still the grading standards EN 14081-2 [7] and EN 14081-2 [8] are based on the assumption that the weakest cross section along the board is in fact tested, i.e. it is implicitly assumed that $f_{t, O, h, \text { test }}=f_{t, O, h \text {, whole }}$. The consequences of this erroneous assumption become very clear comparing the yields of Model 1-grading of test length with the much lower yields of Model 1 (which represents appropriate grading of the entire board). Of course, if $f_{t, O, h, \text { test }}=f_{t, O, h \text {, whole }}$ the two models would give the same yield. Another consequence of the assumption is that too low settings are determined for IPs based on a global board property, like dynamic MOE, when used for prediction of strength. The yield becomes higher than what is appropriate, and the intended safety levels of such graded timber are not obtained.

Model 2 give, just as Dynamic MOE grading, and of the same reasons, too low settings and too high yield in strength classes. Thus, even though Model 2 predicts strength with lower accuracy than what Model 1 does (cf. $\mathrm{r}^{2}=0.61$ for Model 2 and $\mathrm{r}^{2}=0.66$ for Model 1 grading of test length) Model 2 gives higher yield in strength classes than what Model 1 does. In order to decrease the yields of Model 2 to the same yields as for Model 1, the settings for Model 2 would have to be increased as indicated by results presented in Table 8, i.e. by approximately (average over investigated strength classes) 1.3 MPa. However, since Model 2 is less accurate than what Model 1 is, the yield should actually be lower than that of Model 1 and thus the settings for $\mathrm{IP}_{\mathrm{E}, \mathrm{b}, \mathrm{f}, 2}$ should be increased by more than 1.3 MPa. Comparing Model 1-grading of test length with Model 1, results presented in Table 8 show that in order to give the same yield, settings for the former model would have to be increased by about $2.3 \mathrm{MPa}$. This should represent an appropriate correction term to apply for timber from Scandinavia on both Model 2 and Model 1-grading of test length. Application of a correction term of about $2.3 \mathrm{MPa}$ would probably be appropriate also for Dynamic MOE grading but further research is needed to give basis for a precise correction term to apply for Dynamic MOE grading.

The issue with length effects and settings, i.e. that adjustments of settings may be needed for methods like Dynamic MOE grading, was investigated and discussed already in [9] and [10]. Rais and Van de Kuilen [9] suggested that a correction factor of 1.00-1.20 should be applied on settings for an IP based on dynamic MOE. However, two things should be noted regarding their investigation. Firstly, they assumed that the weakest testable cross section is always tested. This means that they probably underestimated the difference between the strength of the tested part of the board and the strength of the entire board, since, as shown herein, it is likely that another cross-section than the weakest testable one is actually tested. Second, the results of [9] did not give basis for correction factors higher than 1.04 to apply on Dynamic MOE grading, except for the class C24 which was the lowest grade investigated. Results of the present study support, however, their suggestion that a correction, (although we would suggest a correction term, rather than a correction factor) should be applied to methods like Dynamic MOE grading.

\subsection{Performance and application of grading method}

Regarding overall performance of the grading method based on fibre direction, which was originally presented in [11] for prediction of bending strength, the present investigation show that the method give basis for very accurate prediction of tensile strength and high yield of timber graded into $\mathrm{T}$-classes. 
Comparisons with results presented in [5], in which the method was evaluated evaluated for grading of timber into C-classes, show that the method is equally efficient for grading of $\mathrm{T}$-classes as it is for grading into C-classes. However, in the study presented in [5] the weakest cross section, as indicated by the calculated bending MOE profile, was always placed within the maximum bending moment zone of a four point bending tests. Therefore, the accuracy and the calculated yield presented in that study are comparable with the accuracy and yield of Model 1-grading of test length of the present investigation. The yield in each strength class, calculated using Model 1-grading of test length, is about the average of the yields obtained using Dynamic MOE grading and Optimum yield (cf. results presented in Table 6). This is also the case for yields in $\mathrm{C}$-classes given in [5].

Finally regarding the alternative models/procedures presented herein, Model 1 is the only one that represents an appropriate grading method that automatically takes length effects, i.e. the fact that the strength of tested parts of boards is generally lower than strength of entire boards, into account. Model 2 would most likely be permitted for industrial application, just as Dynamic MOE grading is, but of reasons that are discussed above, Model 2 is not recommended for practical use. It is presented herein mainly to give basis for evaluation and discussion.

\section{Conclusions}

In this study, a local IP based on surface laser scanning and dynamic excitation for prediction of tensile strength was applied for grading boards to T-classes. Two alternative procedures (Model 1 and Model 2) for derivation of settings and calculation of yield for IPs reflecting a local board property were presented. Both procedures/models would be permitted according to EN 14081-2 [7] and EN 14081-2 [8].

Both Model 1 and Model 2 resulted in considerably higher yields in strength classes, particularly in T22 and higher grades, than what Dynamic MOE grading did. For example, in T22 the yield was 11 and 19 percentage higher, for Model 1 and Model 2, respectively, compared to the yield using Dynamic $M O E$ grading. Furthermore, grading accuracy and yield for boards with sawn surfaces were only slightly lower than the accuracy and yield for planed boards. Thus the proposed grading method based on local fibre orientation, which was originally developed for grading of boards into C-classes (see [5] and [11]), is efficient also for grading of boards into $\mathrm{T}$-classes, both for sawn and planed boards.

Model 2 resulted in a higher yields compared to Model 1 at the same time as the IP applied in Model 1 for prediction of the grade determining strength resulted in higher $r^{2}$ and lower SEE than what the IP applied in Model 2 did. The explanation for these, seemingly contradictory results, was based on the fact that the weakest cross section along a board is not always tested, which means that the actual strength of many board, i.e. the strength of the very weakest cross section, is lower than the strength determined by the tensile test. Using Model 1, this condition, is automatically and appropriately taken into account but using Model 2, and also using Dynamic MOE grading the yields in strength classes become too high. Therefore, Model 2 is not recommended for practical application. Dynamic MOE grading, which has been widely used for many years, should be penalized with a correction term such that settings for strength are increased and the yield in strength classes is decreased. In this respect, the present study support findings of [9]. Results of the present investigation imply that settings for tensile strength should be increased by about $2 \mathrm{MPa}$, to give a fair yield in $\mathrm{T}-$ classes using methods like Dynamic MOE grading.

It has been shown in this paper, that in order to guarantee appropriate safety levels of timber structures, there is a need to further develop the grading standards. Presently, there is considerable risk, using grading methods applying a global board property or the lowest local board property along the whole board as IP to strength, that the minimum requirement of 5-percentile characteristic strength given in EN 338 [1] for a graded class are not fulfilled for timber graded in the daily production.

Acknowledgements Open access funding provided by Linnaeus University. The authors acknowledge the support from Derome Timber, Loab, Microtec, Moelven Töreboda AB, Rörvik Timber AB, Södra Innovasion \& Nya affärer and WoodEye.

Funding This study was funded by the Knowledge Foundation (Grant No. 20150179). 


\section{Compliance with ethical standards}

Conflict of interest The authors declare that they have no conflict of interest.

Open Access This article is licensed under a Creative Commons Attribution 4.0 International License, which permits use, sharing, adaptation, distribution and reproduction in any medium or format, as long as you give appropriate credit to the original author(s) and the source, provide a link to the Creative Commons licence, and indicate if changes were made. The images or other third party material in this article are included in the article's Creative Commons licence, unless indicated otherwise in a credit line to the material. If material is not included in the article's Creative Commons licence and your intended use is not permitted by statutory regulation or exceeds the permitted use, you will need to obtain permission directly from the copyright holder. To view a copy of this licence, visit http://creativecommons.org/licenses/by/4.0/.

\section{References}

1. EN 338 (2016) Structural timber-strength classes. European Committee for Standardisation

2. EN 384 (2016) + A1 (2018) Structural timber-Determination of characteristic values of mechanical properties and density. European Committee for Standardisation

3. Briggert A, Olsson A, Oscarsson J (2020) Prediction of tensile strength of sawn timber: Definitions and performance of indicating properties based on surface laser scanning and dynamic excitation. Mater Struct 53(3). https://doi.org/10.1617/s11527-020-01460-5

4. Hanhijärvi A, Ranta-Maunus A (2008) Development of strength grading of timber using combined measurement techniques. Report of the Combigrade-project-phase 2. VTT Publications 686:55

5. Olsson A, Oscarsson J (2017) Strength grading on the basis of high resolution laser scanning and dynamic excitation: a full scale investigation of performance. Eur J Wood Wood Prod 75:17-31
6. Viguier J, Bourreau D, Bocquet J-F, Pot G, Bléron L, Lanvin J-D (2017) Modelling mechanical properties of spruce and Douglas fir timber by means of X-ray and grain angle measurements for strength grading purpose. Eur $\mathbf{J}$ Wood Wood Prod 75:527-541

7. EN 14081-2 (2010) + A1 (2012) Timber structuresStrength graded structural timber with rectangular cross section-part 2: machine grading; additional requirements for initial type testing. European Committee for Standardisation

8. EN 14081-2 (2018) Timber structures-Strength graded structural timber with rectangular cross section-part 2: machine grading; additional requirements for initial type testing. European Committee for Standardisation

9. Rais A, Van de Kuilen J-WG (2015) Critical section effect during derivation of settings for grading machines based on dynamic modulus of elasticity. Wood Mater Sci Eng 12(4):189-196

10. Rais A, Van de Kuilen J-WG (2010) Assessment of local timber defects during testing and grading as influenced by machine approval procedure. In: Proceedings of the 11th world conference of timber engineering, Riva del Garda, Italy, 4-7 May

11. Olsson A, Oscarsson J, Serrano E, Källsner B, Johansson M, Enquist B (2013) Prediction of timber bending strength and in-member cross-sectional stiffness variation on the basis of local wood fibre orientation. Eur J Wood Wood Prod 71:319-333

12. Ridley-Ellis D, Stapel P, Baño V (2016) Strength grading of sawn timber in Europe: an explanation for engineers and researchers. Eur J Wood Wood Prod 74:291-306

13. EN 408 (2010) + A1 (2012) Timber structures-structural timber and glued laminated timber-determination of some physical and mechanical properties. European Committee for Standardisation

14. TG1 (2018) Decisions. 17th October 2018. CEN TC123/ WG2/TG1

Publisher's Note Springer Nature remains neutral with regard to jurisdictional claims in published maps and institutional affiliations. 